\title{
Tendencias didácticas de la educación virtual: Un enfoque interpretativo
}

\section{Teaching Trends in Virtual Education: An Interpretative Approach}

\author{
Victor F. Pando \\ Universidad Católica Santa María, Arequipa, Perú. \\ Licenciado en Educación e Ingeniero de Sistemas. Docente de Postgrado.
}

Recibido 07-07-17 Revisado 30-10-17 Aprobado 23-01-18 En línea 24-01-18

*Correspondencia

Email: vpandob@ucsm.edu.pe

\section{Citar como:}

Pando, V.F (2018). Tendencias didácticas de la educación virtual: Un enfoque interpretativo. Propósitos y Representaciones, 6(1), 463-505. doi: http://dx.doi.org/10.20511/pyr2018.v6n1.167

(C) Universidad San Ignacio de Loyola, Vicerrectorado de Investigación, 2018

(cc) BY-NC-ND Este artículo se distribuye bajo licencia CC BY-NC-ND 4.0 Internacional (http://creativecommons.org/licenses/by-nc-nd/4.0/). 


\section{Resumen}

En el contexto teórico de las discusiones sobre tendencias didácticas de la educación virtual, particularmente para la educación superior, la presente investigación desarrolla una interpretación de algunas tendencias, redimensionando lo registrado por otros autores al respecto. Para ello, se procedió a un estudio de carácter documental, con enfoque interpretativoanalítico. Los resultados arrojan que la tendencia de la Didáctica tecnológica se puede desarrollar a través de las corrientes conductista y conectivista, en las que subyace una deshumanización del individuo ante procesos de enseñanza-aprendizaje de carácter tecnocéntrico, en virtud de que prevalecen en estos procesos algunas amenazas de la virtualización y escasa atención a sus principales fortalezas. Se concluyó que el impacto de las TIC rompe con algunas expectativas puestas en ellas, para la mejora del quehacer pedagógico, al tiempo que se recomienda abordar la tendencia de la didáctica crítica como una perspectiva de reflexión sobre las pedagogías emergentes del entorno virtual.

Palabras claves: Tendencias didácticas, educación virtual, didáctica tecnológica, conductismo, conectivismo.

\section{Summary}

Based on the theoretical context of discussions about teaching trends in virtual education, particularly for higher education, this research develops an interpretation of some of these trends, resizing what was registered about it by other authors. To that end, a documentary study with an interpretativeanalytical approach was carried out. The results show that the Technological Didactics trend can be developed through the behavioral and connectivism theories, in which the dehumanization of the individual is concealed in teaching-learning processes of a technocentric nature, since in these processes, there are some virtualization threats and little attention to their main strengths. It was concluded that the impact of ICT deconstructs some 
expectations placed on them to improve the pedagogical task. In addition, it is recommended to address the Critical Didactics trend as a perspective of reflection on emerging pedagogies of the virtual environment.

Keywords: Teaching trends, virtual education, technological didactics, behaviorism, connectivism. 


\section{Introducción}

Con el avance tecnológico, las propuestas de educación virtual buscan ser revolucionarias, con el interés de influir positivamente en los procesos de enseñanza-aprendizaje. De manera que existen tendencias didácticas, generadas sobre la base de determinados modos de percibir las tecnologías de información y comunicación (TIC), así como de formas de emplear las mismas con la pretensión de sacarles el mayor provecho posible, y de eliminar las barreras que pudieran existir en la utilización de la virtualidad aplicada a la educación.

La realidad empírica ha demostrado que la praxis educativa del docente está mucho más relacionada con la educación presencial, que lo que el profesorado quiere admitir: las evidencias confirman que los modelos didácticos que pudieran ajustarse académicamente a la educación virtual, han sido soslayados por muchos docentes de todos los niveles educativos.

Es importante, entonces, poner en foco de discusión, desde un enfoque interpretativo, algunas tendencias didácticas de la educación virtual, mediante una deconstrucción de las mismas, distinguiendo, desde una perspectiva teórica, dos tendencias generales: la clásica y la innovadora.

\section{El problema.}

Aun cuando el desarrollo de la docencia dentro del entorno virtual no es tan reciente; sin embargo, las didácticas parecieran haberse quedado en estilos presenciales de praxis educativa, por parte del docente e incluso en los imaginarios de los estudiantes. Los docentes, en sus conocimientos, actitudes y prácticas, inserta sus didácticas en tales estilos y el estudiante aún sigue siendo un mero receptor.

Sin embargo, tal como lo afirman Duart y Sangrá (2010, p. 7), las posibilidades didácticas de la educación virtual son innumerables y "requieren de una metodología que ha de cambiar la manera en que 
tradicionalmente el profesorado enseña y los estudiantes aprenden", lo cual indica que los procesos de enseñanza-aprendizaje experimentan un tránsito por determinadas transformaciones que se producen mediante las herramientas virtuales.

Eldeber ser apuntala a una transformación de los propósitos educacionales, sus objetivos, secuencias, metodologías y evaluaciones que, en el entorno virtual, generan otro sentido de los procesos de enseñanza aprendizaje, que contrasta diametralmente con el enfoque meramente transmisor que ha sido el rol del docente. Asimismo, el aprendizaje ha obedecido al estilo pasivo del estudiante, en su rol de aprendiz de contenidos de la cultura vigente, los cuales debe saber replicar en las circunstancias que se ameriten.

Por ello, al momento de enseñar, son fundamentales el concepto, los objetivos, métodos y la evaluación de la enseñanza, que, para el profesorado, bien pueden ser asumidos tanto clásica como innovadoramente, obteniéndose beneficios y desventajas bajo cada una de esas perspectivas. Tal como lo expresa Lara (2001, p. 133), "existe el dilema de las teorías de enseñanzaaprendizaje en el entorno virtual".

Respecto a la confrontación entre conductismo y constructivismo en el entorno virtual, se ha sugerido por muchos autores, utilizar una estrategia mixta en donde se utilicen las ventajas de ambas teorías. Por ejemplo, explica Lara (2001) que:

La perspectiva conductista debe ser utilizada fundamentalmente para el manejo de los aspectos de tipo organizativo como la definición de la estructura del proceso, la enunciación de objetivos y el manejo de las evaluaciones. La perspectiva constructivista se debe utilizar para el manejo de los aspectos eminentemente académicos como la definición de estrategias de interacción y para definir las actividades individuales y grupales que contribuirán al logro de los objetivos (p. 134).

Asimismo, existen otras tendencias didácticas en el entorno virtual, tales como la teoría de la conversación, la teoría del conocimiento situado, la teoría conectivista, que intentan romper con didácticas clásicas en los procesos de 
enseñanza aprendizaje (PEA). En ellas, lo fundamental es la responsabilidad del discente en la construcción de su aprendizaje, el docente como mediador y evidentemente, el papel instruccional que se asigna a las TIC.

No obstante, los elementos de la educación virtual, aparentemente innovadores, han sido implícitos: se desconocen abiertamente, los fines, metas y propósitos de un tipo de educación que esté inmersa en el contexto virtual. Ni se diga acerca de las secuencias y métodos necesarios para que sea exitosa. Los estilos de praxis educativa del docente mediado por las TIC, y los PEA, a la luz de tendencias didácticas, en todos los niveles educativos, aún permanecen tácitos y cada profesor trabaja “a su manera”. Esta problemática abre una discusión sobre tales tendencias.

De ese modo, se promueve un interés investigativo por indagar distintos planteamientos teóricos acerca de las tendencias didácticas de la educación virtual, e interpretarlos en términos de su utilidad para los PEA. La necesidad e importancia de tal búsqueda consiste en abrir un espacio de reflexión que pueda aprovecharse para conformar nuevas discusiones sobre las posibilidades didácticas que posee la educación virtual. Así, surge la siguiente interrogante: ¿Qué resultados se obtienen de interpretar distintas tendencias didácticas de la educación virtual?

\section{Argumentación}

\section{Antecedentes de la investigación}

En Puerto Rico, Casanova (2016) presenta una ponencia ante la EDP University, titulado El docente virtual: un cambio al paradigma tradicional. El objetivo de este estudio consistió en ofrecer a los docentes un panorama general sobre las competencias necesarias para ejercer como educador virtual, y así promover la calidad de la modalidad de enseñanza mediada por la tecnología, que es solo un medio, con el fin último de transformar a través de la educación. Para ello, la autora desarrolla una investigación documental, 
cuyos resultados demuestran que el rol del docente ha cambiado a través de los años para atemperarse a la realidad de la generación de estudiantes que reciben y al mundo globalizado al que se enfrentan los profesionales.

Igualmente, concluye que, ante una generación altamente tecnológica y la pronta inmersión de los nativos digitales, es meritorio considerar la importancia del rol docente e identificar las áreas de mayor oportunidad para su desarrollo, puesto que la modalidad virtual de enseñanza trae consigo muchos retos y uno de los más significativos es el constante cambio tecnológico y sus implicaciones en las didácticas.

En Colombia, Padilla, Vega y Rincón (2014), publican un artículo científico presentado a la Universidad Militar Nueva Granada, titulado Tendencias y dificultades para el uso de las TIC en educación superior. Esta investigación tuvo como objetivo comprender, desde una perspectiva reflexiva, la importancia de una pedagogía flexible, sistémica y basada en los aportes de un docente con consciencia histórica que permita superar obstáculos en el proceso de educación virtual o semipresencial.

La metodología de este estudio consistió en una revisión documental de diferentes textos científicos en clave hermenéutica, y en la utilización de procedimientos de codificación axial y abierta. Los autores obtuvieron que, a partir de los memorandos creados para la clasificación de la información con apoyo del software "ATLAS.ti”, a manera de resultados, se agenciaron las dificultades que pueden existir en la apropiación de las TIC a través del fundamento pedagógico constructivista y sistémico.

En ese sentido, el aporte investigativo se centró en valorar el rol del docente y la importancia de su estilo de enseñanza, teniendo claridad del papel sustancial de la pedagogía en la apropiación de las TIC para potenciar contenidos, recursos, materiales y actividades encaminados a facilitar el aprendizaje autónomo y colaborativo de los estudiantes. Concluyen los autores que son relevantes la formación permanente y la autoevaluación que lleve a cabo el docente de su praxis pedagógica. 
En Cuba, Lombillo, López y Zumeta (2012) desarrollaron una investigación para la Universidad Agraria de la Habana, titulada Didáctica del uso de las TIC y los medios de enseñanza tradicionales en las Instituciones de Educación Superior (IES) municipalizadas. Este estudio tuvo como objetivo caracterizar la práctica actual en la que se basa el uso de los medios de enseñanza en el aula universitaria cubana en su segunda etapa, como parte de una de las tareas del proyecto de investigación "Perfeccionamiento del proceso de universalización en las sedes Universitarias Municipales de la provincia de La Habana. Generalización de resultados y desarrollo de experiencias innovadoras contextualizadas". Se concibió el estudio en once Instituciones de Educación Superior (IES) municipalizadas de Cultura Física de la provincia seleccionada durante cuatro cursos académicos (2007-2009) y (2009-2011).

Se aplicó la metodología descriptiva mediante la utilización de la observación, la encuesta y la escala de actitudes "Diferencial semántico de Osgood" como métodos y técnicas fundamentales. Los resultados globales alcanzados en las dos etapas de investigación, revelaron que los profesores manifiestan un uso ocasional, no sistémico y con cierta tendencia a una actitud de desaprobación del uso de los medios de enseñanza, particularmente las $\mathrm{TIC}$ en el proceso de enseñanza-aprendizaje semipresencial.

Los antecedentes reseñados se vinculan con la presente investigación en virtud de que posibilitan la argumentación acerca del impacto que tienen las TIC en las didácticas de los docentes y en los procesos de enseñanzaaprendizaje, así como acerca de las debilidades didácticas para afrontar la educación virtual.

De lo anterior se deduce que existen tendencias didácticas en la educación virtual que tienen en su haber dificultades y retos a enfrentar: requerimientos importantes y urgentes que la praxis docente debe considerar, dado que las tecnologías generan las denominadas por Adell y Castañeda (2012, p. 15) como «pedagogías emergentes», entendidas como un conjunto de enfoques e ideas pedagógicas, "todavía no bien sistematizadas, que surgen alrededor 
del uso de las TIC en educación y que intentan aprovechar todo su potencial comunicativo, informacional, colaborativo, interactivo, creativo e innovador en el marco de una nueva cultura del aprendizaje”. Así, valga señalar que, en palabras de García (2017, p. 9), "el aprendizaje digital está suponiendo una disrupción educativa porque plantea un cambio drástico de soportes y métodos". En virtud de lo expuesto, se plantean los siguientes ejes temáticos que sustentan la argumentación.

\section{Ejes temáticos: tendencias didácticas, educación virtual.}

Las tendencias didácticas pueden concebirse como el modelo, enfoque, perspectiva del pensamiento al que propende determinado estilo de praxis docente. Según Pino (2010: 1), el término tendencias didácticas "para denominar determinados conceptos de la realidad pedagógica y de la educación se ha venido complejizando en los últimos años". Por su parte, Sánchez-Toledo (citada en Pino, 2010: 1) las define como un "conjunto de posiciones teórico pedagógicas, enlazadas por un núcleo común, que generalmente agrupa a varios seguidores quienes la sustentan, divulgan y pueden llevarla a la práctica educacional”. De manera que resulta de interés investigativo considerar el eje temático tendencias didácticas, como constructo que da forma a los procesos de enseñanza-aprendizaje (PEA) como contexto de aplicación de la educación virtual.

En eta investigación, las tendencias didácticas generales son clasificadas en clásicas o tradicionalistas y las innovadoras. Con respecto a las primeras, Pino (2010: 1) explica que las mismas se caracterizan por concebir el acto didáctico como una tríada que tiene como centro el proceso instruccional; considera la posición del profesor como sujeto principal y genera un aprendizaje receptivo; el énfasis lo centra en las relaciones personales maestro-alumno y no entra a considerar la riqueza de las interrelaciones entre los componentes personales y personalizados del PEA. 
Los contenidos se basan en el enciclopedismo donde el esfuerzo del discente radica en la memorización y repetición, se utiliza la exposición del profesor y el discente asume fundamentalmente el rol del espectador; se sobrevalora el verbalismo en detrimento de la observación sistemática y la experiencia vivida; por último, la evaluación del aprendizaje se ha caracterizado esencialmente por una comprobación de la transmisión de conocimientos, por tanto, se considera una actividad terminal con una función mecánica, e incluso como arma de intimidación (Pino, 2010). Esta tendencia se vincula estrechamente con el conductismo, racionalismo y academicismo, donde el PEA se centra en el profesor.

Mientras tanto, en las tendencias didácticas innovadoras: la Nueva Escuela Clásica (Pino, 2010), el Modelo Alostérico (Giordan, como se citó en Añez, Becerra, \& Bousquet, 2003), Didáctica tecnológica (Pino, 2010), Didáctica crítica, entre otras, los PEA se centran en el discente.

Valga iniciar el recorrido por estas tendencias, con la corriente cognitivistaconstructivista, uniéndolas artificialmente debido a los elementos comunes de ambas. En esta corriente, derivada de las críticas al modelo clásico tradicionalista, se considera la importancia del papel del discente como sujeto cognoscente activo, constructor, descubridor de conocimiento. Sin embargo, tal enfoque pedagógico es criticado por Giordan (como se citó en Añez, Becerra, \& Bousquet, 2003, p. 4), expresando que: "no solo es suficiente atender a los aspectos y mecanismos conceptuales de los alumnos; existe un sinnúmero de relaciones interdependientes socio-culturales (el aula, la escuela, la familia etc.) que juegan un papel importante en el aprendizaje".

De modo que el precitado autor propone lo que denomina Modelo Alostérico, que se basa en que "los conceptos no son entidades individualizadas o independientes entre sí, sino que conforman redes semánticas de significados; aunado a esta dinámica, es necesario considerar la dinámica del contexto sociocultural donde ocurre el aprendizaje" (Giordan, como se citó en Añez, Becerra, \& Bousquet, 2003, p. 4). Asimismo, el constructivismo social (Carretero, 2009) considera el contexto. 
A los anteriores modelos centrados en el discente, pero, los dos últimos, yendo un paso más al considerar el entorno sociocultural de aprendizaje, se unen los modelos de la Didáctica Neoclásica y la Didáctica Tecnológica como tendencias pedagógicas. Al respecto, Pino (2010, p. 1) afirma que la perspectiva Neoclásica considera el contexto sociocultural, sin embargo, "tiene la limitación de que provoca un proceso espontáneo en la enseñanza que impide una mayor orientación y control de las acciones del discente".

Por otra parte, respecto a la tendencia de la didáctica tecnológica, según Pino (2010), ésta se caracteriza, entre otros, por los siguientes aspectos:

El proceso mismo de aprendizaje es el que minimiza el papel del maestro centrando su atención en el medio como soporte material del método. -No hay un proceso de reflexión que permita el reconceptualizar el marco teórico de sus propuestas. -En la implantación, el alumno se somete a la tecnología, a los programas instruccionales, supuestamente de acuerdo con su ritmo personal y sus diferencias individuales, a los instrumentos de enseñanza: libros, máquinas, procedimientos, técnicas -Se replantea el rol del profesor que pasa ahora de aquel que domina el contenido al que domina las técnicas, lo que le permite continuar controlando la situación educativa. -La evaluación trata de medición, avalando así el carácter observable y medible del aprendizaje. (p. 1)

De manera, que aun cuando este enfoque está centrado en el discente, sus características muestran que el profesor tiene un nuevo tipo de control (técnico) sobre las situaciones de aprendizaje y parece haber una vuelta de hoja hacia el conductismo, en especial, en cuanto al sistema de evaluación del PAE. Para Pino (2010) esta tendencia de la didáctica tecnológica posee una influencia conductista, aun cuando exista en ella una cierta fuerza en los niveles de cooperación e interdependencia de los alumnos.

Asimismo, dentro de este tipo de didáctica se encuentra el conectivismo, que consiste, según algunos autores, en "una teoría del aprendizaje para la era digital desarrollada por George Siemens y por Stephen Downes para explicar el efecto que la tecnología ha tenido sobre la manera en que actualmente vivimos, nos comunicamos y aprendemos" (Ovalles, 2014, p. 73), corriente 
que es considerada un paradigma educativo actual, con características que serán puestas en discusión más adelante.

Este recorrido culmina con una tendencia didáctica de carácter innovador, denominada Didáctica Crítica, que tuvo su auge en los años 80 en algunos países de América Latina; para Pino (2010, p. 1), se centró en "la educación no escolarizada, con un peso humanista al enfatizar en el papel del sujeto, en contacto con la realidad social y los problemas de la sociedad". La didáctica crítica se contrapone al cognitivismo y otras corrientes, al aupar elementos afectivos, valorativos y emocionales.

Por su parte, Añez, Becerra y Bousquet (2003, p. 12) caracteriza esta tendencia como aquella que "propicia el desarrollo sistémico de las categorías interpretativas de los enseñantes y ayuda al desarrollo de comunidades autorreflexivas que garanticen la unión de la teoría con la práctica, entre otros aspectos".

Ahora bien, es importante inscribir un concepto acerca de Educación virtual. la cual se clasifica, generalmente, en las modalidades e-learning (o a distancia), y b-learning (semipresencial). En concreto, la educación virtual es "el uso de tecnologías basadas en Internet para proporcionar un amplio abanico de soluciones que aúnen adquisición de conocimiento y habilidades o capacidades" (Aguilar, 2015, p. 34).

Resulta de interés destacar que la integración de las TIC a la educación será exitosa "cuando el sistema educativo, pueda diseñar un aprendizaje significativo, producto de vivencias experienciales y un contenido reflexivo, capaz de generar en el alumno y docente el logro de generar conocimiento" (Hernández, 2017, p. 333). Esta búsqueda requiere de un abordaje de procesos alternativos de enseñanza-aprendizaje (PEA).

Valga definir los PEA como aquellas relaciones entre docente y discentes, (y entre pares), orientada "al movimiento de la actividad de los alumnos bajo la dirección del maestro, hacia el dominio de los conocimientos, las habilidades, los hábitos y la formación de una concepción científica del 
mundo" (Ortiz, 2009, p. 1). Para el precitado autor, dichas relaciones son dialécticas, y sus componentes son los objetivos, el contenido, los métodos, los medios y su organización los que conforman una relación lógica interna.

La educación virtual no escapa a la asunción de ese mismo concepto de PEA, con la diferencia de que los componentes se mueven dentro del espacio de las tecnologías, en particular, la Internet, lo que transforma sustancialmente los roles de docente, discente y el diseño instruccional a ser manejado en dicho espacio. De acuerdo con De Pablo (2017, p. 54): un factor imprescindible para obtener un mejor aprendizaje, “"es el pensamiento metodológico de la organización de un curso online, es decir, el docente ha de proveer de recursos y actividades que persigan alcanzar diferentes competencias que responden a diferentes objetivos de aprendizaje". De esa manera, sostiene la precitada autora, "el docente ocupará otro rol: el de mediar en el proceso entre la información y el conocimiento que llamamos aprendizaje".

\section{La tendencia de la didáctica tecnológica.}

En principio, cabe citar a Aguilar (2015, p. 31) cuando afirma que el auge de la educación virtual, "ha ido en paralelo a una tecnología que cada vez más ha desarrollado la relación e interacción entre participantes a través de las redes de comunicación". De manera que los procesos de enseñanza-aprendizaje se han ido, cada vez más, orientando y conformándose según didácticas alternativas, donde, los objetivos, el contenido, los métodos, los medios y su organización, se ven influidos por relaciones entre docente-discente y entre pares, que, ahora, son desarrolladas en un contexto comunicacional más inmediato, más veloz, dominado por el «tecnocentrismo» y la virtualidad.

Por tal motivo, para la interpretación de algunas tendencias didácticas de la educación virtual, es necesario, antes, destacar los beneficios, aunque también las desventajas de la transformación de los procesos de enseñanzaaprendizaje bajo didácticas alternativas, con el auge de la educación virtual; 
lo que es lo mismo, desplegar las fortalezas y las amenazas del contexto comunicacional tecnocéntrico y virtual, para tales procesos.

En tal sentido, se recurre a Aguilar (2015, p. 357), quien afirma que la inmediatez de la información posibilita "un alto protagonismo a los participantes como creadores y recreadores de su propia cultura gracias a esa interconexión ágil, flexible, interactiva, asíncrona y de tiempos fluidos que supone lo virtual".

De manera que, toda propuesta didáctica que pretenda ser alternativa, debe acoger la inmediatez y la flexibilidad que posibilita la virtualidad, con sus ventajas para la masificación de la educación, al trascender tiempo y espacio, y facilitando los estudios a personas cuyas características le impidan una formación presencial o semipresencial. Valga indicar que, en la virtualidad, se ha destacado el uso educativo de dispositivos móviles, lo que "aumenta las ventajas propias del aprendizaje flexible al romper aún más las barreras espaciotemporales” (García, 2017, p. 20).

Ahora, respecto a la relación entre participantes, la virtualidad supone una: "enorme capacidad como medio facilitador para la coparticipación, las relaciones y comunicación social y el intercambio activo de significados" (Aguilar, 2015, p. 357). Esto aúpa teorías de aprendizaje colaborativo como teoría didáctica para la educación virtual, tal es el caso de los planteamientos de Suárez-Guerrero y Muñoz (2017, p. 369), quienes afirman que "la cooperación y la participación dotan de sentido y significado al trabajo en red".

Ahora, con respecto a las amenazas del contexto comunicacional dominado por la virtualidad y la inmediatez; según Bauman (2015, p. 117), con ello se ha generado una «modernidad líquida»: una sociedad fluida, con nexos frágiles y valores poco sólidos, de cambios vertiginosos y alta incertidumbre". De manera que "el cambio de la historia moderna del tiempo alude al impacto que está empezando a ejercer sobre la condición existencial 
humana. El cambio en cuestión es la nueva irrelevancia del espacio, disfrazado como aniquilación del tiempo" (Bauman, 2015, p. 126).

Las consecuencias negativas de la virtualidad en el ámbito educativo, son indiscutibles. Entre ellas, se ha perdido el contacto con el entorno físico, de importancia para el aprendizaje. Aunado a esto, valga citar a Domínguez e Ybañez, (2016, p. 183) quienes sostienen que la inadecuada utilización de la virtualidad "ha puesto en riesgo algunas formas de comunicación habitual... poco a poco se han ido deteriorando las relaciones familiares, sociales y laborales", lo que incide en el aprendizaje. Por ejemplo, la bien conocida búsqueda incesante de contenidos en las redes sociales pareciera dar la respuesta a los intereses, necesidades y motivaciones de los discentes; lo cual luce alejado de sus requerimientos relacionales, académicos, emocionales y axiológicos.

Entonces, los procesos de enseñanza-aprendizaje, la praxis docente, y otros contextos (epistémicos) del quehacer educativo se ven implicados en un norte no deseado por los sistemas educativos, y éstos pueden sentirse impotentes ante la avalancha de contenidos comunicacionales que sustituyen un aprendizaje y una conducta, acordes con los objetivos educativos formales.

Por otra parte, revisando la tendencia de la Didáctica tecnológica, serán consideradas dos corrientes en que ella puede concretarse: el conductismo y el conectivismo. El conductismo, aplicado al entorno virtual, señala el rol central del docente, la receptividad pasiva del discente, el papel instruccional de las TIC, donde, el control que es de carácter técnico, recae sobre los medios y el profesor, y la evaluación es una medición con enfoque intimidatorio y punitivo.

Por otra parte, el conectivismo se caracteriza por "tomas de decisión que son en sí mismas un proceso de aprendizaje. Escoger qué aprender y el significado de la información entrante es visto a través de la lente de una realidad cambiante" (Ovalles, 2014, p. 77). Este aspecto, quizá visto como una fortaleza ya que refuerza el rol del discente como centro del PEA, es 
cuestionable y puede llegar a ser una gran amenaza para la educación virtual y sus propuestas didácticas.

Al respecto, puede el lector darse cuenta de la vulnerabilidad de los actores educativos (tanto docente como discentes) ante la avalancha de mensajes y contenidos virtuales que hacen que los procesos de enseñanzaaprendizaje se basen en la internalización de múltiples y cuestionables criterios para filtrar la información, no discutidos ni explícitos, además, sujetos a transformación continua, que pueden generar que los componentes de los PEA sean desviados de los propósitos educativos ideales y formales.

Asimismo, la característica del conectivismo, que hace que esta corriente sea innovadora, es señalada por el Ministerio de Educación del Perú (Ministerio de Educación del Perú, 2016, p. 7), y resumida de la siguiente manera: "trabajar es involucrarse en una comunidad". Lo cual es igualmente cuestionable, puesto que, en la educación virtual, la comunidad y su concepto ha cambiado con las TIC; en este sentido, Aguilar (2015, p. 36) afirma que: "en los contextos virtuales cambia el valor situacional, la relación dialógica, la mediación y por extensión las formas de convivir...nos preguntamos por la figura de la nueva identidad de los grupos primarios en red y en comunidad".

Las relaciones docente-discente, entre pares y con la comunidad globalizada, posibilitan el reforzamiento del aprendizaje colaborativo y cooperativo, sobre lo cual, el conectivismo ha hecho consideración al plantear que: "el conocimiento se produce como producto de interacción entre los miembros" (Ministerio de Educación del Perú, 2016, p. 7). No obstante, tal como bien señala Aguilar (2015, p. 376): "nos cuestionamos si es posible el aprendizaje cooperativo en entornos virtuales de aprendizaje en cuanto al nivel de compromiso dialógico y crítico [presente en] los postulados de construcción social del conocimiento de la teoría socio cultural”.

De manera que el presente discurso logra desembocar en la tendencia Didáctica crítica, anteriormente explicada, donde la ideología respecto a los 
PEA y sus didácticas son de relevancia para abordar desde otras visuales la problemática que origina esta investigación, conformando una tarea pendiente para la comunidad académica interesada en la educación virtual.

Mientras tanto, valga puntualizar los hitos del discurso hasta este momento: el conectivismo surgió como una corriente alternativa pedagógica, enmarcada dentro de la Didáctica tecnológica. Esta didáctica se ha comportado, desde algunos componentes de manera conductista, en particular, en cuanto al condicionamiento, definido por el Ministerio de Educación del Perú (2016, p. 6) como aquella praxis docente "basada en estímulos y respuestas". Pero, aun cuando pertenece a la didáctica tecnológica, el conectivismo trasciende al condicionamiento, debido a las razones arriba explicadas.

Por otra parte, el conectivismo como tendencia didáctica de la educación virtual amenaza en cierta forma, la condición humana en relación a sus problemas existenciales, a sus nexos sociales, sus valores, debido a lo denominado, siguiendo a Bauman (2004), como generación de la modernidad líquida. Entonces, emerge una nueva interrogante: ¿el conectivismo ha resultado ser un nuevo conductismo? ¿tiene utilidad para la mejora de los procesos de enseñanza-aprendizaje?

\section{La didáctica tecnológica en términos de su utilidad en la mejora de los procesos de enseñanza-aprendizaje (PEA).}

En las tendencias clásicas que, en este estudio, se concretan en la corriente conductista, el aprendizaje es denotado en que hay un cambio o transformación en el comportamiento ("la mente es una caja negra"), y se considera que la realidad es externa y "objetiva" (Ministerio de Educación del Perú, 2016, p. 6). La supuesta objetividad científica soslaya los factores y mecanismos internos del discente para aprender. De allí la asignación de un rol de receptor pasivo.

Pero, por otra parte, bajo esa misma tendencia conductista, evidenciada en numerosas aulas virtuales, existe un control técnico por parte del 
docente de las situaciones de aprendizaje, con la respectiva utilidad que ello representa para evitar la divagación de ideas, contenidos, mensajes comunicacionales que provee la red, de modo que se mantienen los criterios para filtrar la información con la finalidad de que ésta sí logre contribuir con los objetivos instruccionales. Sin embargo, es condicionante y los PEA impiden el aprendizaje significativo, con un discente que no construye su conocimiento.

Respecto al conectivismo, corriente en la que se ha centrado la tendencia alternativa tecnológica para la educación virtual, "el aprendizaje es diverso y complejo... se adquiere el conocimiento cuando se necesite" (Ministerio de Educación del Perú, 2016, p. 7). Por ende, el control del profesor es mínimo; redunda la divagación de ideas, contenidos y mensajes comunicacionales de toda naturaleza. Entonces, las relaciones docente-discente se transforman y en este devenir se extravían los objetivos instruccionales. Por ende, el conectivismo pareciera pertenecer a la Nueva Escuela Clásica, en el sentido de que provoca un proceso espontáneo en la enseñanza que impide una orientación y un control de las acciones del discente.

Asimismo, la didáctica tecnológica en su corriente conectivista, tiene otro elemento sujeto a cuestionamiento, para lo cual, vale la pena recurrir a Zapata (2011, p. 1), quien afirma que en la sociedad de la información "el ritmo de novedades hace que una verdad nueva sustituya a la antigua sin tiempo para actuar con la parsimonia que la ciencia exige, y sin validar la verdad aceptada.". Por esta razón, entre otras, el precitado autor cuestiona que la teoría del conectivismo posea elementos sólidos para tornarse en un modelo didáctico.

De manera que el conectivismo tiene mucho camino por andar, por ejemplo, la vía de la Didáctica crítica, por donde la auto-organización, la complejidad y el caos, propios de esa teoría, logren ser orientados en función de una verdadera utilidad para los procesos de enseñanza-aprendizaje. Para ello, sería fundamental la implantación de «aulas virtuales creativas», de 
cuya creación se tiene conocimiento, pero sobre las cuales su impacto ha sido escasamente evaluado o validado en función del PEA.

Por otra parte, existen teorías aparte del conductismo y conectivismo, tales como cognitivismo, constructivismo, constructivismo social, modelo alostérico, entre otras, que dan cuenta de tendencias didácticas actuales y que, mediante el desarrollo de trabajos investigativos de campo, podrían emerger como propias de determinada comunidad virtual educativa. Tales corrientes no son desdeñables, y fueron mencionadas en su momento; pero el punto álgido de la discusión radicó en contrastar corrientes extremas, lo que condujo a conocer que el conductismo está vinculado al conectivismo en la medida en que ambas corrientes robotizan al ser humano, y aun cuando la segunda trasciende a la primera en múltiples aspectos y por las diversas razones explicadas, ambas se enmarcan en la didáctica tecnológica; donde, la primera se cruza con la didáctica clásica y la segunda con la neoclásica.

\section{Conclusiones}

Las corrientes de la Didáctica tecnológica deshumanizan. En el primer caso, por exceso del control implicado en el cumplimiento de los objetivos instruccionales, desarrollado en base a una teoría de carácter condicionante, por ende, lejana a la naturaleza humana; y en el segundo, por falta de una didáctica y teoría del aprendizaje concretas, que permitan criterios pedagógicos y diseños instruccionales claros y explícitos, lo cual convierte al hombre en esclavo de la tecnología sin saber a ciencia cierta lo que aprende, por qué lo aprende, y lo que, en definitiva, realmente quiere y necesita aprender.

De manera que la tendencia de la Didáctica tecnológica, tanto desde el modelo conductista como desde el conectivista, demuestran poca o nula consideración a las relaciones dialécticas, presentes en el quehacer pedagógico, y por ello, el impacto de las TIC rompe con algunas expectativas puestas en ellas, para la mejora de los procesos de enseñanza-aprendizaje, que 
ha encontrado en esa tendencia escasa utilidad: los objetivos, el concepto, métodos, organización, componentes de tales procesos, obvian el rol del discente como constructor de su aprendizaje, o si lo hace, entonces, deriva en procesos espontáneos de aprehensión de conocimientos bajo criterios indefinidos y probablemente, alejados de ideales educativos formales. Esto influye negativamente en el discente, tanto en lo académico, como en lo emocional y axiológico.

Por otra parte, la consideración del contexto sociocultural, que aplica tanto para el modelo alostérico como al constructivismo social, entre otros modelos propios de tendencias innovadoras, es abordada por la Didáctica tecnológica, desde el punto de vista de relaciones en el marco de la virtualidad, $\mathrm{y}$, por ende, el entorno físico tiende a ser soslayado, o medianamente asumido en el caso de procesos de enseñanza-aprendizaje semipresenciales. En cualquier caso, prevalecen en dichos procesos las interrelaciones virtuales, consideradas, en buena medida, una amenaza para el aprendizaje y para los objetivos educacionales ya que se pierden nexos con el entorno que proveen al discente de un aprendizaje significativo, a cambio de la inmediatez que surte la tecnología, de una información que podemos llamar líquida.

La alternativa frente a este panorama sería el desarrollo de «aulas virtuales creativas» que cumplan la condición de que el docente bajo criterios reflexivos, aborde el diseño de metodologías alternativas vinculadas a enfoques de carácter sociocultural, en consideración a que las TIC, conforme avanzan las nuevos adelantos, transforman las cosmovisiones en general, incidiendo esto en las perspectivas sobre los procesos educativos: Por esta razón, tanto los criterios como la presencia del docente deben ser flexibles, considerar la inmediatez, y su actuación ser consecuente con ello.

Esta investigación debe continuar con nuevas interrogantes que posibiliten afrontar de manera crítica la problemática de las tendencias actuales de la educación virtual, que trascienda la mera interpretación. Con esto se abordarían las ideologías presentes en dichas tendencias para abrir una nueva discusión sobre el tema, bajo una reflexión que acoja la tendencia 
de la Didáctica critica para la educación virtual, en el marco del diseño de aulas virtuales creativas que generen mejoras en los procesos de enseñanzaaprendizaje en todas sus dimensiones.

\section{Referencias}

Adell, J., \& Castañeda, L. (2012). Tecnologías emergentes, ¿pedagogías emergentes? En J. Hernández, M. Pennesi, D. Sobrino y A. Vázquez (coord.). Tendencias emergentes en educación con TIC. Barcelona, Asociación Espiral, Educación y Tecnología, (pp. 13-32).

Aguilar, D. (2015). Ser docente virtual: tiempo y presencia (Tesis doctoral). Universidad de Málaga, España.

Añez, E., Becerra, R., \& Bousquet, M. (2003). Tendencias didácticas actuales: Modelo Alostérico y Crítico. Recuperado de: http://app.ute.edu. ec/content/3344-23-59-1-23-17/PAPEL\%20DE\%20TRABAJO\%20 CUATRO\%20TENDENCIAS\%20DIDÁCTICAS.pdf

Bauman, Z. (2015). Modernidad líquida ( $3^{\mathrm{a}}$ ed.). Buenos Aires: Fondo de Cultura Económica.

Carretero, M. (2009). Constructivismo y Educación. Buenos Aires: Editorial Paidós.

Casanova, A. (2016). El docente virtual: un cambio al paradigma tradicional. Conferencia presentada en el Seminario Desarrollo Profesional Docente: formación, evaluación y certificación. Recuperado de: http://acceso. virtualeduca.red/documentos/ponencias/puerto-rico/1419-8509.pdf

De Pablo, G. (2017). Factores que favorecen la presencia docente en entornos virtuales de aprendizaje. Tendencias pedagógicas, 29, 43-58. doi: https:// doi.org/10.15366/tp2017.29.001

Domínguez, J., \& Ybañez, J. (2016). Adicción a las redes sociales y habilidades sociales en estudiantes de una institución educativa privada. Propósitos y Representaciones, 4(2), 181 - 230. doi: http://dx.doi. org/10.20511/pyr2016.v4n2.122

Duart, J., \& Sangrá, A. (2010). Aprender en la virtualidad. (2 ${ }^{\mathrm{a}}$ ed.). Barcelona: Gedisa. 
García, L. (2017). Educación a distancia y virtual: calidad, disrupción, aprendizajes adaptativo y móvil. Revista Iberoamericana de Educación a Distancia, 20(2), 09-25. doi: http://dx.doi.org/10.5944/ried.20.2.18737

Hernández, R.M. (2017). Impacto de las TIC en la educación: Retos y Perspectivas. Propósitos y Representaciones, 5(1), 325 - 347. doi: http:// dx.doi.org/10.20511/pyr2017.v5n1.149

Lara, L. (2001). El dilema de las teorías de enseñanza-aprendizaje. Revista Cientifica de Comunicación y Educación, 17, 133-136.

Lombillo, I., López, A., \& Zumeta, E. (2012). Didáctica del uso de las TIC y los medios de enseñanza tradicionales en las Instituciones de Educación Superior (IES) municipalizadas. New Approaches In Educational Research, 1(1), 38-46.

Ministerio de Educación del Perú (2016). Módulo 4: TIC para la enseñanza y el aprendizaje. Programa de capacitación en Didácticas Aplicadas a la Educación Técnica [en línea] Recuperado de: http://gead.minedu. gob.pe/digesutpa/

Ortíz, K. (2009). Plataforma para el control del uso de softwares educativos [en línea]. Recuperado de: http://www.eumed.net/librosgratis/2009c/583/ Proceso\%20de\%20ensenanza\%20aprendizaje.htm

Ovalles, L. (2014). Conectivismo ¿un nuevo paradigma en la educación actual? Revista FESC, 1(7), 72-79.

Padilla, J., Vega, P., \& Rincón, D. (2014). Tendencias y dificultades para el uso de las TIC en educación superior. Revista Entramado, 10(1), 272295.

Pino, R. (2010). Tendencias didácticas. Definiciones y propuestas. Revista IPLAC, 3 .

Suárez-Guerrero, C., \& Muñoz, J.L. (2017). El trabajo en red y la cooperación como elementos para la mejora escolar, Propósitos y Representaciones, 5(1), 349-402. doi: http://dx.doi.org/10.20511/pyr2017.v5n1.150

Zapata, M. (2011). ¿Es el “conectivismo” una teoría? ¿Lo es del aprendizaje? [blogcued.blogspot.pe]. Recuperado de: http://blogcued.blogspot. com/2011/09/es-el-conectivismo-una-teoria-lo-es-del.html 